\title{
Efectiveness of Ocimum sanctum Linn. Leaves Ethanol Extract on Mortality Raillietina echinobothrida In Vitro
}

\section{Efektivitas Daun Kemangi (Ocimum sanctum Linn.) Terhadap Kematian Raillietina echinobothrida Secara In Vitro}

\author{
1) Jessica Giovani, ${ }^{2)}$ Setiawan Koesdarto, ${ }^{3)}$ Mirni Lamid, ${ }^{4)}$ Sri Agus Sudjarwo, ${ }^{2)}$ Muchammad \\ Yunus, ${ }^{5}$ Suryo Kuncorojakti \\ ${ }^{1)}$ Student, ${ }^{2)}$ Department of Parasitology, ${ }^{3)}$ Department of Animal Husbandry, ${ }^{4}$ Department of Basic \\ Medical Veteriner, ${ }^{5}$ Department of Anatomi Veteriner. Faculty of Veterinary Medicine, Universitas \\ Airlangga.
}

\begin{abstract}
The aims of the research are to prove the anthelmintic effects of Ocimum sanctum Linn. leaves ethanol extract on Raillietina echinobothrida in vitro and to know the value of $\mathrm{LC}_{50}$ and $\mathrm{LC}_{90}$ of Ocimum sanctum Linn. leaves ethanol extract. The research used completely randomized design. The research had five treatments and each treatment was done in four replications. The research used ${ }_{5}$ Raillietina echinobothrida adult worms for each treatment and all replications. The observation and the recording were done at the first hour until the sixth hour of the research. The Raillietina echinobothrida adult worms were noted dead if there was no movement when they were disturbed by anatomic tweezer, the death of Raillietina echinobothrida were confirmed when they dipped mildly in warm water $\left(50^{\circ} \mathrm{C}\right)$ and they showed no movements. The acquired data was analyzed using ANOVA and continued with LSD (5\%). The results were Ocimum santum Linn. ethanol extract has the anthelmintic activity in $1.25 \%, 2.5 \%, 5 \%$ and $10 \%$ concentrations. The $\mathrm{LC}_{50}$ and $\mathrm{LC}_{90}$ was analyzed using probit analysis. The results of $\mathrm{LC}_{50}$ calculation were $7.8 \%$ at the third hour, $6 \%$ at the forth hour, $3.2 \%$ at the fifth hour, $2.5 \%$ at the sixth hour and the results of $\mathrm{LC}_{90}$ were $6.5 \%$ at the fifth hour, $5.2 \%$ at the sixth hour. The higher concentration of the extract, the higher anthelmintic activity worked.
\end{abstract}

Key words : Ocimum sanctum Linn. leaves, ethanol extract, Raillietina echinobothrida, in vitro

\section{Introduction}

Tapeworm infection disease remains as a harm problem both in developed or developing countries. Raillietinasis is an important parasitic disease in poultry caused by the genus of Raillietina, particularly Raillietina echinobothrida, the most influential species in terms of prevalence and pathogenicity in domestic fowls (Khohlring, 2010). Infection of the tapeworms in livestock specifically in domestic fowls beside sucking the nutrients and blood of the host, they also cause the damage to certain organs. In mild infection of Raillietina echinobothrida, there are indigestion and growth problem. In heavy infection, there are anemia, conspicuous intestinal nodules in chicken with hyperplastic enteritis associated with the formation of granuloma, sometimes the nodule perforates the intestine causes peritonitis, manifestation of nerve to death (Khohlring, 2010; Tabbu, 2002; Shahin, 2011). Moreover, the infestation of tapeworms in domestic fowls could induce the economic loss of the poultry farmers incurred due to the fowls weight loss.

The control of Raillietiniasis massively was handled with modern synthetic chemical anthelmintics, such as Albendazole and Bunorat. the repeated usage of these chemical anthel- 
mintic medicines, nevertheless, resulted various problems, there is development of resistance, chemical residues and toxicity issues (Husain, 2008). The idea of substituting the synthetic anthelmintic medicine with herbal anthelmintic if it is proven to react towards the mortality of Raillietina echinobothrida has considerably risen.

Indonesia as the rich country has many various kinds of herbal plants which have been observed as an anthelmintic, one of them is Ocimum sanctum Linn. Ocimum sanctum Linn., leaves contain phytochemical constituents, such as eugenol oil, saponin, tannin and flavonoid which are potential to be the alternative herbal anthelmintic (Sentana, 2010), it possessed some anthelmintic activity against nematodes, particularly ascarids, it tested in vitro showed potent anthelmintic activity towards the Caenorhabditis elegans (Kanojiya, 2015; Asha, M. K. et al., 2001). The effectiveness of Ocimum sanctum Linn. leaves towards cestode worms, chiefly Raillietina echinobothrida has never been observed, however.

The present research aimed to know the effectiveness of Ocimum sanctum Linn. leaves ethanol extract on mortality of Raillietina echinobothrida, to know the most optimum concentration of Ocimum sanctum Linn. as anthelmintic and also to know the Ocimum sanctum Linn. leaves ethanol extract values of $\mathrm{LC}_{50}$ and $\mathrm{LC}_{90}$.

\section{Materials and Methods \\ Research Location and Time}

This research was finished in four places, the sequence was UPT Materia Medica Batu, Badan Penelitian dan Konsultasi Industri Surabaya, Wonokromo poultry market Surabaya and Parasitology Laboratory, Faculty of Veterinary Medicine, Universitas Airlangga.

\section{Research Materials and Equipments}

The materials used in this research were the Ocimum sanctum Linn., leaves ethanol extract, the Raillietina echinobothrida tapeworms from Wonokromo poultry market, CMC-Na, 0.9\% PBS solution, $96 \%$ ethanol, warm water $\left(40^{\circ}-45^{\circ} \mathrm{C}\right)$.

The equipments that used in this research were anatomic tweezers, petri dish with $15 \mathrm{~cm}$ diameter, electronic scale, beaker glass, glass rod, oven, stove, thermometer, incubator, canon microscope, stationery for recording and camera for documentation.

\section{Preparation of Ocimum sanctum Linn. Leaves Ethanol Extract}

Fresh Ocimum sanctum Linn. leaves was purchased from UPT Materia Medica, Batu, Malang, East Java on February 2017. The basil leaves was washed thoroughly with fresh running water. The Ocimum sanctum Linn. leaves which had been cleaned were dried with oven in 50--$60^{\circ} \mathrm{C}$ heat. The dried Ocimum sanctum Linn. leaves were pulverized with grinder into powder, the powder used for the extraction.

The Ocimum sanctum Linn. leaves powder was macerated in $96 \%$ ethanol for five days at room temperature and on the first six hours it was stirred with a glass rod manually and repeated once twice a day in five days. After five days, the macerated solutions were filtered with cotton pad and filter paper. The residues were macerated again until the color turned to clear green, the obtained filtrate was combined and condensed with rotary evaporator $50^{\circ} \mathrm{C}$ until the extract became viscous (Noviana, 2015) and the color turned to clear brown. The extract was stored in refrigerator with temperature about $4^{\circ} \mathrm{C}$.

\section{Collection of Raillietina echinobothrida}

The adult tapeworms of Raillietina echinobothrida were collected from the small intestine of the domestic chicken which slaughtered in Wonokromo poultry market, Surabaya. The whole small intestines of chicken were brought to Parasitology Laboratory, Faculty of Veterinary Medicine, Universitas Airlangga. The adult Raillietina echinobothrida worms were identified by their scolex which attached to the mucosa of the chicken duodenum then confirmed under the light microscope and also by the average body length from the measurement.

\section{Research Design and Procedure}

The research was an experimental research which completely randomized to determine effect of basil leaves (Ocimum sanctum Linn.) ethanol extract on mortality of Raillietina echinobothrida in vitro. The extraction used maceration method to prepare the Ocimum 
sanctum Linn. leaves extract and there were five treatments groups in this research which contained 0.5\% CMC-Na solvent, the Ocimum sanctum Linn. leaves ethanol extract suspension with $1.25 \%, 2.5 \%, 5 \%$ and $10 \%$ concencentrations.

Five treatment groups in this research were:

Control (C): 5 tapeworms was put into petri dish with $40 \mathrm{ml}$ of $0.5 \%$ CMC-Na solvent. Treatment 1 ( $\left.\mathrm{T}_{1}\right): 5$ tapeworms were put into petri dish with $40 \mathrm{ml}$ of Ocimum sanctum Linn., leaves ethanol extract suspension with $1.25 \%$ concentrations. Treatment $2\left(\mathrm{~T}_{2}\right): 5$ tapeworms were put into petri dish with $40 \mathrm{ml}$ of Ocimum sanctum Linn., leaves ethanol extract suspension with $2.5 \%$ concentrations. Treatment $3\left(\mathrm{~T}_{3}\right): 5$ tapeworms were put into petri dish with $40 \mathrm{ml}$ of Ocimum sanctum Linn., leaves ethanol extract suspension with $5 \%$ concentrations. Treatment $4\left(\mathrm{~T}_{4}\right): 5$ tapeworms were put into petri dish with $40 \mathrm{ml}$ of Ocimum sanctum Linn., leaves ethanol extract suspension with $10 \%$ concentrations.

Time observations had been done every one hour for six hours. All the petri dishes was put in incubator with temperature $37^{\circ} \mathrm{C}$ (Jagadeesan et al., 2014).

\section{Observation of the Changes}

The observation was done by recorded the death of the tapeworm or the live tapeworm by its movements. The worm was disturbed with anatomic tweezer or was shaken vigorously. The death of the worms was confirmed when the worms did not show any movements after vigorous shake and after introduced them into warm water $\left(50^{\circ} \mathrm{C}\right)$ by mildly dipping the worms into the petridish with $50^{\circ} \mathrm{C}$ water inside (Jagadeesan et al., 2014).
In this research, the researcher analyzed the data used Analysis of Variance (ANOVA), then continued with LSD and Duncan Multiple Range Test to analize the data variance between the treatment groups and control group. The calculation of $\mathrm{LC}_{50}$ and $\mathrm{LC}_{90}$ was analyzed using probit analysis. The analysis was done using SPSS version 20 for windows as the statistical analysis program.

\section{Results}

\section{The Observation of the Dead Raillietina echinobothrida}

The observation of the dead Raillietina echinobothrida was done by noted the number of dead Raillietina echinobothrida in five treatment groups, which are control group, $1.25 \%$ concentration $\left(\mathrm{T}_{1}\right), 2.5 \%$ concentration $\left(\mathrm{T}_{2}\right), 5 \%$ concentration $\left(\mathrm{T}_{3}\right)$ and $10 \%$ concentration $\left(\mathrm{T}_{4}\right)$ every one hour in six observation hours.

The Table 1 and the Figure 1 showed the observation data of dead Raillietina echinobothrida, at the first observation hour, the $10 \%$ concentration was the only concentration that had showed anthelmintic activity, it was significantly different with other concentrations. At the second observation hour, the $10 \%$ concentration still the only concentration that had showed the anthelmintic activity with significant difference.

The third observation hour showed the treatment group of $5 \%$ concentration had showed the death of Raillietina echinobothrida, there was significant difference compared to $2.5 \%$ concentration. The $10 \%$ concentration at this hour also showed significant difference with $5 \%$ concentration.

Table 1. The Dead Raillietina echinobothrida in Every Treatments at All Observation Hours

\begin{tabular}{lcccccc}
\hline Treatment & 1 & 2 & 3 & 4 & 5 & 6 \\
\hline Control (To) & $0.00^{\mathrm{a}} \pm 0.0$ & $0.00^{\mathrm{a}} \pm 0.0$ & $0.00^{\mathrm{a}} \pm 0.0$ & $0.00^{\mathrm{a}} \pm 0.0$ & $0.00^{\mathrm{a}} \pm 0.0$ & $0.25^{\mathrm{a}} \pm 0.5$ \\
$1.25 \%\left(\mathrm{~T}_{1}\right)$ & $0.00^{\mathrm{a}} \pm 0.0$ & $0.00^{\mathrm{a}} \pm 0.0$ & $0.00^{\mathrm{a}} \pm 0.0$ & $0.50^{\mathrm{ab}} \pm 0.6$ & $1.50^{\mathrm{b}} \pm 0.6$ & $3.00^{\mathrm{b}} \pm 0.8$ \\
$2.50 \%\left(\mathrm{~T}_{2}\right)$ & $0.00^{\mathrm{a}} \pm 0.0$ & $0.00^{\mathrm{a}} \pm 0.0$ & $0.00^{\mathrm{a}} \pm 0.0$ & $1.00^{\mathrm{b}} \pm 0.0$ & $2.25^{\mathrm{c}} \pm 0.5$ & $3.25^{\mathrm{b}} \pm 0.5$ \\
$5.00 \%\left(\mathrm{~T}_{3}\right)$ & $0.00^{\mathrm{a}} \pm 0.0$ & $0.00^{\mathrm{a}} \pm 0.0$ & $1.00^{\mathrm{b}} \pm 0.0$ & $2.25^{\mathrm{c}} \pm 0.5$ & $3.00^{\mathrm{d}} \pm 0.0$ & $4.00^{\mathrm{c}} \pm 0.0$ \\
$10 \%\left(\mathrm{~T}_{4}\right)$ & $0.25^{\mathrm{b}} \pm 0.5$ & $1.75^{\mathrm{b}} \pm 0.5$ & $3.0^{\mathrm{c}} \pm 0.6$ & $4.00^{\mathrm{d}} \pm 0.0$ & $4.75^{\mathrm{e}} \pm 0.5$ & $5.00^{\mathrm{d}} \pm 0.0$ \\
\hline
\end{tabular}

Values are expressed as mean $\pm \mathrm{SD}$, the different superscript of $\mathrm{a}, \mathrm{b}, \mathrm{c}, \mathrm{d}$, e in same column show significant difference $(\mathrm{p}<0.05)$ 


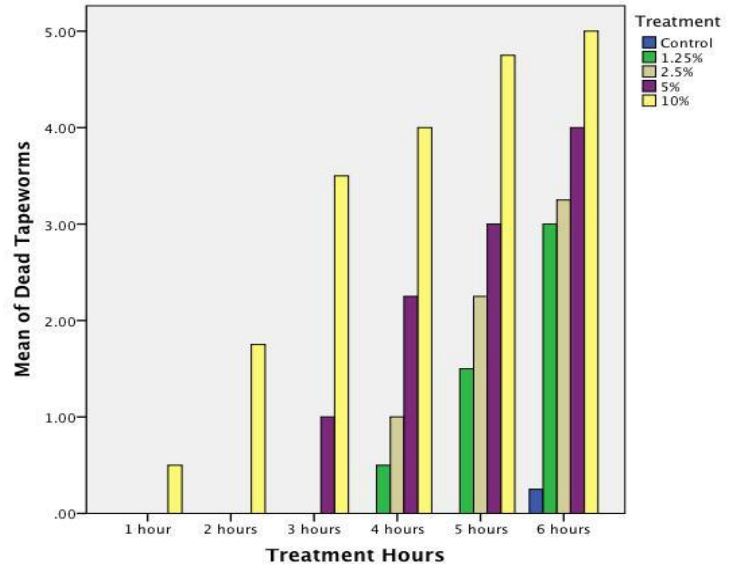

Figure 1. Showing The Effect of Ocimum sanctum Linn. Leaves Ethanol Extract to The Average Numbers of Dead Raillietina echinobothrida in Each Concentrations at Each Observation Hours.

The forth observation hour in treatment group of control and $1.25 \%$ had not been showed difference significantly. The $1.25 \%$ concentration and the $2.5 \%$ concentration had showed the death of Raillietina echinobothrida, but no significantly different. The $2.5 \%$ concentration and the $5 \%$ are significantly different at this hour. The $5 \%$ concentration and the $10 \%$ concentration showed significant difference as well.

The fifth observation hour in the treatment group of control and the $1.25 \%$ concentration had showed significant difference. The $1.25 \%$ the $2.5 \%$ concentration had also showed significant difference, the $2.5 \%$ and the $5 \%$ concentration had also showed significant difference and the $5 \%$ and $10 \%$ concentration has also showed the significant difference, but the $10 \%$ concentration showed the highest average number of dead Raillietina echinobothrida at the fifth hour. The dead Raillietina echinobothrida was found in all treatments groups at sixth observation hour, the significant difference was happened between every treatment groups at this last observation hour.

\section{$\mathrm{LC}_{50}$ and $\mathrm{LC}_{90}$}

The value of $\mathrm{LC}_{50}$ and $\mathrm{LC}_{90}$ of Ocimum sanctum Linn. Ethanol extract was calculated using probit analysis with log base 10. The $\mathrm{LC}_{50}$ and the $\mathrm{LC}_{90}$ in all observation hours can be seen in Table 2. Based on the Table 2, it can be known the value of $\mathrm{LC}_{50}$ at 1, 2, 3, 4, 5, and 6 observation hours are $13.8 \%, 12.1 \%, 7.8 \%, 6 \%, 3.2 \%$ and $2.5 \%$. The $10 \%$ concentration had been able to kill $50 \%$ population of Raillietina echinobothrida at the third hour, the $5 \%$ and $2.5 \%$ concentration had been enough to kill $50 \%$ population of Raillietina echinobothrida, but in longer exposure time. The $\mathrm{LC}_{90}$ of Ocimum sanctum Linn. ethanol extract are $6.5 \%$ at the fifth hour and $5.2 \%$ at the sixth hour.

The $10 \%$ concentration is the only concentration that was able to kill $90 \%$ population of Raillietina echinobothrida.

Table 2. The Value of $\mathrm{LC}_{50}$ and LC9o of 'Ocimum sanctum Linn. Ethanol Extract in Every Observation Hours.

\begin{tabular}{ccc}
\hline $\begin{array}{c}\text { Observation } \\
\text { Hour }\end{array}$ & $\mathrm{LC}_{50}$ & $\mathrm{LC}_{90}$ \\
\hline 1 & $13.8 \%$ & $28.1 \%$ \\
2 & $12.1 \%$ & $24.5 \%$ \\
3 & $7.8 \%$ & $15.8 \%$ \\
4 & $6 \%$ & $12 \%$ \\
5 & $3.2 \%$ & $6.5 \%$ \\
6 & $2.5 \%$ & $5.2 \%$ \\
\hline
\end{tabular}

\section{Discussion}

The research results from the data analysis with ANOVA continued with LSD can be found out that the result was significant difference $(\mathrm{p}<0.05)$. The observation at the first hour showed there was still no anthelmintic activity of Ocimum sanctum Linn. ethanol extract in the $1.25 \%$ concentration group ( $\left.\mathrm{T}_{1}\right)$, the $2.5 \%$ concentration group ( $\left.\mathrm{T}_{2}\right)$ and the $5 \%$ concentration group ( $\left.\mathrm{T}_{3}\right)$, but the $10 \%$ concentration group $\left(\mathrm{T}_{4}\right)$ had showed the anthelmintic activity and there was already significant difference between $10 \%$ concentration and other concentrations. The observation result at the second hour, the anthelmintic activity of Ocimum sanctum Linn. was not clearly showed in the concentrations of $1.25 \%\left(\mathrm{~T}_{1}\right), 2.5 \%\left(\mathrm{~T}_{2}\right), 5 \%\left(\mathrm{~T}_{3}\right)$, that can be inferred from the not significant difference average number of the dead Raillietina echinobothrida among these groups, but still only the $10 \%$ concentration group $\left(\mathrm{T}_{4}\right)$ had showed the anthelmintic activity to Raillietina echinobothri$d a$, it can be seen from the significant difference of $10 \%$ concentration $\left(\mathrm{T}_{4}\right)$ group with others group. 
The observation at the third hour showed the anthelmintic activity of Ocimum sanctum Linn. leaves ethanol extract began to appear at $5 \%$ concentrations $\left(\mathrm{T}_{3}\right)$. The $5 \%$ concentration group has also showed significant difference with the $1.25 \%$ and $2.5 \%$ concentrations group, it also was significantly different with the $10 \%$ concentration group. The $10 \%$ concentration group showed the anthelmintic activity of Ocimum sanctum Linn. leaves ethanol extract increased during the immersion time got longer, it showed higher average number of dead Raillietina echinobothrida and also significant difference with $5 \%$ concentration group which means the Ocimum sanctum Linn. leaves ethanol extract with $10 \%$ concentration is more effective.

The Ocimum sanctum Linn. leaves ethanol extract in each concenctrations at the forth observation hour had showed the anthelmintic activity. The Ocimum sanctum Linn. leaves ethanol extract with $1.25 \%$ concentration had even showed the anthelmintic activity, but from the statistic analysis, the result showed that the $1.25 \%$ concentration did not make the significant difference with the control group. The 2.5\% concentration also showed anthelmintic at this hour, but statistically had no significant differrence with $1.25 \%$ concentration which means the $1.25 \%$ was more effective at this hour. The $5 \%$ concentration showed the increased number in the average number of the dead Raillietina echinobothrida. Beside that, the $10 \%$ concentration at this observation hour continually increased the amount of dead Raillietina echinobothrida, from the analysis data the average number of dead Raillietina echinobothrida in Ocimum sanctum Linn.

The Ocimum sanctum Linn. leaves ethanol extract at the fifth observation hour showed the anthelmintic activity against the Raillietina echinobothrida more effective. The average number of the dead Raillietina echinobothrida in each concentration groups was increased. At this hour, the difference between each concentration appeared significantly. The Ocimum sanctum Linn. leaves ethanol extract with $10 \%$ concentration in this hour successfully almost killed all the Raillietina echinobothrida, it can be inferred from the death percentage that has reached more than $90 \%$ of tapeworms population in this hour. The Ocimum sanctum Linn. at the sixth observation hour which is the last observation hour showed the anthelmintic activity clearly with the highest effectivity, it can be seen from the number of the average number of the dead Raillietina echinobothrida was highly increased in each concentration group. The Ocimum sanctum Linn. leaves ethanol extract with $1.25 \%$ and $2.5 \%$ concentration showed no significant difference in their anthelmintic activity, because there was only small amount difference in average number of dead Raillietina echinobothrida, that means $1.25 \%$ concentration was enough and more effective than $2.5 \%$ concentration at this hour. The average number of the dead Raillietina echinobothrida in the $2.5 \%$ concentration and $5 \%$ concentration showed significant difference, the statistical analysis showed $5 \%$ concentration worked more effective than the $2.5 \%$ concentration. The last observation hour showed that the Ocimum sanctum Linn. leaves ethanol extract with $10 \%$ concentration has the highest average number of the dead Raillietina echinobothrida.

Dead Raillietina echinobothrida was also found in the control group which contained CMC-Na that was dissolved in PBS solution. The death percentage was quite small, it was only about $5 \%$, it might be happened because of the in vitro method. The research has been designed as simulant as the host body condition, but still the different physiological condition and the environment orientation might affected the condition of Raillietina echinobothrida. In fact, CMC---Na has already been used in many fields, especially in pharmaceutics, food and chemical industries (Musfiroh and Budiman, 2013).

The Ocimum sanctum Linn. leaves has been proven that it has important phytochemical constituents to be anthelmintic, there were phenolics, flavonoid, tannin, saponin and eugenol (Karumari et al., 2014). Tannin could act as anthelmintic indirectly by increasing the protein availability for enhancing the immunelogical responses of host to helminthes (Athanasiadou et al., 2001). Tannins and phenolics are known to act with the energy generation in helminthes by uncoupling the oxidative phosphorylation, binding to free proteins in the host gastrointestinal and leading to death, that ability made tannins could also inhibit enzymatic 
activity in metabolic pathway of the worms (Athanasiadou et al., 2001; Hoste et al., 2006). Saponin is worked by increasing the permeability of the helminth body wall, it could cause the vacuolization (Parvathy et al., 2012). The essential oil of Ocimum sanctum Linn. which named eugenol is showed possible utilization in the treatment of gastrointestinal helminthes, it has already been proven that eugenol has potent anthelmintic activity towards the Caenorhabditis elegans and Haemonchus contortus (Pessoa et al., 2002). The effective anthelmintic activity of Ocimum sanctum Linn. leaves ethanol extract might be supported by the used of Ocimum sanctum Linn. leaves from UPT Materia Medica, Batu, Malang where the Ocimum sanctum Linn. was came from a good quality of seeds and grew with a good set maintenance.

The comparation in each treatment groups at every observation hours was analyzed statistically for the second time using probit analysis to determine the $\mathrm{LC}_{50}$ and the $\mathrm{LC}_{90}$ of Ocimum sanctum Linn. leaves ethanol extract at every observation hours. The $\mathrm{LC}_{50}$ at 1, 2, 3, 4, 5 , and 6 observation hours are 13.8\%, 12.1\%, 7.8\%, $6 \%, 3.2 \%$ and $2.5 \%$. The $\mathrm{LC}_{90}$ of Ocimum sanctum Linn. ethanol extract at first hour is $28.1 \%, 24.5 \%$ at the second hour, $15.8 \%$ at the third hour, $12 \%$ at the forth hour, $6.5 \%$ at the fifth hour and at the sixth hour is $5.2 \%$.

Based on the research results, that can be known that the longer immersion time of the Raillietina echinobothrida the lower concentration that needed to kill $50 \%$ or $90 \%$ population of Raillietina echinobothrida as well. The $10 \%$ concentration of Ocimum sanctum Linn. leaves ethanol extract in term of exposure time was the fastest concentration whom showed the anthelmintic activity, at the very first observation hour it had showed the anthelmintic activity, it even had been able to kill 50\% population sample at the third hour and it had been able to kill 90\% population sample at the fifth hour.

\section{Conclusions}

Based on the the research results, there can be concluded that the ethanol extract suspension of Ocimum sanctum Linn. leaves in $1.25 \%$, 2.5\%, $5 \%$ and $10 \%$ concentrations have the anthelmintic activity towards Raillietina echinobothrida in vitro. The $\mathrm{LC}_{50}$ of Ocimum sanctum Linn. leaves ethanol extract is $7.8 \%$ at the third hour, $6 \%$ at the forth hour, $3.2 \%$ at the fifth hour and the $2.5 \%$ at the sixth hour. The $5 \%$ had been effective to kill $50 \%$ population of Raillietina echinobothrida at fifth observation hour. The $\mathrm{LC}_{90}$ of Ocimum sanctum Linn. leaves ethanol extract is more than $10 \%$ at the first and until the forth hour, $6.5 \%$ at the fifth hour and $5.2 \%$ at the sixth hour. The $10 \%$ concentration in accordance of the $\mathrm{LC}_{50}$ and $\mathrm{LC}_{90}$ value of Ocimum sanctum Linn. leaves ethanol extract is the most optimum concentration as the anthelmintic towards Raillietina echinobothrida.

\section{References}

Asha, M. K., D. Parasanth, B. Murali, R. Padmaja and A. Amit. 2001. Anthelmintic Activity of Essential Oil of Ocimum sanctum and eugenol. Elsevier Science B.V.: Fitoterapia 72 (2001) 669---670.

Athanasiadou, S., I. Kyriazakis, F. Jackson, and R. L. Coop. 2001. Direct anthelmintic effects of condensed tannins towards different gastrointestinal nematodes of sheep in vitro and in vivo studies. Vet. Parasitol. 99, 205-219.

Hoste, H., J. Frank, A. Spiridoula, M. T. Stig and O. H. Simone. 2006. The Effects of Tannin rich Plants on Parasitic Nematodes in Ruminants. Science Direct J. Trends in Parasitology, Vol. 22, No. 6.

Hussain, A. 2008. Evaluation of Anthelmintic Activity of Some Ethnobotanicals. Faculty of Veterinary Science. University of Agriculture Faisalabad Pakistan.

Jagadeesan, K., T. George, M. N. Kamalanathan, and T. Ilyaraja 2014. Studies on the Anthelmintic and Antioxidant Activity of Root Extracts of Elytratria Acaulis. Research of Animal and Veterinary Sciences, Department of Zoology, President College, Vol. 2, Issue 8, Page 457, 2014. 